\title{
A problem for the idea of voluntary euthanasia
}

\author{
Neil Campbell University of Calgary, Alberta,Canada
}

\begin{abstract}
I question whether, in those cases where

physician-assisted suicide is invoked to alleviate unbearable pain and suffering, there can be such a thing as voluntary euthanasia. The problem is that when a patient asks to die under such conditions there is good reason to think that the decision to die is compelled by the pain, and hence not freely chosen. Since the choice to die was not made freely it is inadvisable for physicians to act in accordance with $i t$, for this may be contrary to the patient's genuine wishes. Thus, what were thought to be cases of voluntary euthanasia might actually be instances of involuntary euthanasia.
\end{abstract}

(Fournal of Medical Ethics 1999;25:242-244)

Keywords: Euthanasia; voluntary; ethics; philosophy

Current debates over physician-assisted suicide are frequently centred on the distinction between "active" and "passive" euthanasia: whether killing has a different moral status from allowing one to die, and whether, under certain conditions, the intended killing of another human being is ethically permissible. There is, however, a more fundamental distinction which is often presupposed in the background of these discussions but which is seldom explored. This is the distinction between "voluntary" and "involuntary" euthanasia. I suppose the reason for the lack of interest in this distinction is that it is pretty clear that involuntary euthanasia is not ethically permissible, regardless of the situation. It seems obvious enough that taking the life of another human being, against his or her will, is immoral whether the person in question is terminally ill and in tremendous pain or not. On the other hand, if the patient wishes to end his or her life under such conditions the moral evaluation of euthanasia becomes much more complicated. Thus, most would accept the claim that involuntary euthanasia is impermissible, regardless of whether it is active or passive. The assumption is, then, that when discussing the active-passive distinction, the concern is for voluntary euthanasia. The lack of critical attention paid to the voluntary-involuntary distinction seems to be a mistake. For if it turnss out that the distinction is not as clear cut as most ethicists assume, then the debate over thळ active-passive distinction could turn out to bề irrelevant because the cases that were thought to be voluntary might actually be involuntary. M黛 aim in this discussion is to show that this is possibility that should be taken seriously.

Let us begin with a brief sketch of the distinction between voluntary and involuntary actions. Although there is insufficient space here to do this adequately, we can say a certain amoundo if we remain at the level of practical common sense, which should serve us well since we are here concerned with practical matters that arise in reas life, and not just philosophical contexts. An action is voluntary if it is freely chosen. It is, I hope, relatively uncontentious claim to say that action is freely chosen if it is not compelled. Peo $\frac{3}{3}$ ple acting on posthypnotic suggestions or doing what they think the devil tells them to are not actê. ing voluntarily because their choices are com pelled by forces beyond their control: in the firs case by the planted suggestion, and in the secon case by the mental illness or delusion. Nor can a action be regarded as free if it is compelle® contrary to what the agent wishes. If my arm is being forcibly moved by someone else and I an powerless to prevent its motion no matter how strongly I might will otherwise, then the motion of my arm is involuntary. Thus, it seems that we car say at least this: an action is involuntary if it is not freely chosen or is compelled in opposition to the्E agent's wishes, and voluntary if otherwise. While this is at best a cursory account of the voluntaryo

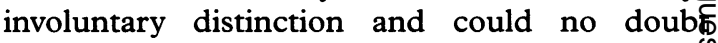
benefit from further elaboration and investigation? it is, in its present form, sufficient for the rest o뭉 my discussion and should appear to be triviall true.

When it comes to discussions of physician@ assisted suicide it is, under certain conditions uncertain whether there can be a clear distinction between voluntary and involuntary euthanasia The vast majority of cases in which the question af euthanasia arises concern those in which the 
patient, who is terminally ill, is inflicted with "unbearable" pain and suffering. (My arguments will leave untouched those cases in which pain and suffering are not a factor but where other qualityof-life issues are the main consideration). In order for either active or passive euthanasia to be characterised as voluntary the patient must freely will that his or her life be ended. But how is this possible? If the pain and suffering are by definition unbearable, then it seems clear enough that the decision to die is not freely chosen but is compelled by the pain. Consider the analogy of the prisoner who is tortured for information. When he finally gives in we tend to think that the prisoner is not responsible for revealing state secrets. The assumption is that since the pain was so excruciating the decision to talk was not voluntary, but was compelled. Indeed, that is the whole point of torture. Under the conditions of unbearable pain and suffering, then, if the concern of the agent is to alleviate the pain it seems to be a mistake to speak of voluntary choices. The natural conclusion to draw from this is that there can be no such thing as voluntary euthanasia, or, at the very least, that we have no means to ensure that the patient's request to die was not compelled. If we cannot be sure about this it seems as though euthanasia ought not to be permitted, for it then becomes something which is, or might be, done contrary to the patient's own wishes.

One might argue that although the pain is a determining factor in the decision to end one's life, the decision to do so is fully rational and therefore ought to be obeyed. If one is in the situation envisaged and the pain is too much to bear, and one knows that the only way to relieve the pain is by accelerating one's death, either by stopping medical treatment or by more direct means, then it is rational to choose to end one's life. There is therefore no reason to think that such choices are irrational or irresponsible and ought not to be followed. But whether or not the decision to die is rational is beside the point. By ordinary standards of rationality it is rational to ask that one's life be terminated when faced with unbearable pain and suffering, but so is the prisoner's decision to tell his torturers what they want to know. The prisoner knows that if he reveals the requested information the torture will stop. Since he doesn't wish to be tortured any longer the rational thing to do is to reveal the state secrets. The rationality of the act is not what is important when it comes to assessing whether it is free and whether it is morally advisable to act in accordance with it. Even though it is rational to tell one's captors what they want to know we do not find victims of torture responsible for giving out information when they have been tortured. It seems to me that a similar conclusion holds in the case of requests for assisted suicide. Even though it is rational to end one's life under certain conditions this doesn't mean that such requests are made freely. If the request to end one's life is not made freely, then it is doubtful that such requests ought to be followed.

\section{Living wills}

These considerations might only be seen to concern those cases in which the patient has not expressed any wishes concerning physicianassisted suicide before reaching the point in an illness where the pain and suffering become unbearable. Thus, one might think that living wills can serve as a reliable source of evidence for the patient's true wishes and can therefore be used to get around the identified problem. When we no longer have any assurance that the patient is able freely to choose to die, the living will can be regarded as a kind of proxy for free decision making. But this is not without its own difficulties. Consider a thirty-five-year-old person who formulates a living will which dictates that he be killed or allowed to die if he is ever in the situation of enduring unbearable pain and suffering as the result of a terminal illness. If this happens thirty years later it is only prudent to ask whether the person in question still wants his earlier instructions to be followed or if he has changed his mind. It is quite possible that this individual's views on the matter have changed over the course of time. If we do not ask him until he is actually in the situation of being in the described pain, then we face the problem identified earlier. We have no way of ensuring that his decision to adhere to his earlier wishes was made voluntarily. Given this, the logical thing to do is to ask the patient whether we are to abide by his earlier wishes shortly before the illness develops to the point where pain and suffering become unbearable, in which case we would have a reasonable assurance of what his wishes will be when he reaches that point.

This seems to be a satisfactory strategy, but it is unclear whether or not it is entirely successful. Just as it was prudent to ask whether or not the patient might have changed his mind over a thirty-year period, it seems prudent to acknowledge the possibility that he might change his mind over the period of several weeks, days, or even hours. Perhaps, despite the pain and in light of his impending death, he has come to value life more than he ever did before. Since we are here dealing with a human life, the wishes of the patient are of the highest concern. Thus, we seem to have a moral obligation to determine the patient's wishes 
at the last possible moment, which will be when he is enduring tremendous pain and suffering, but then we are right back where we started. Whether a living will was made thirty years ago or thirty hours ago seems to make no difference, at least not a difference in kind. We therefore have no way of ensuring that the patient's desire to end his life is freely chosen, and so, even with living wills it appears as though euthanasia (whether active or passive) is not permissible where unbearable pain and suffering are concerned.

We have seen, then, that there are legitimate reasons for questioning whether or not there can be such a thing as voluntary euthanasia. In those cases where the decision to end one's life is made when experiencing unbearable pain and suffering we cannot rule out the possibility that the choice to end one's life was not made freely. In those cases where a living will is in existence we have a moral obligation to ensure that the patient still wishes us to abide by the terms of the will, but t每. do this we need to determine the patient's wishes at the latest possible time, in which case we end uf with the same problem just mentioned. If the above arguments are correct, then the currer debates about active and passive euthanasia are unnecessary, at least for certain types of cases, fo either form of euthanasia turns out to be involum tary, and most ethicists agree that involuntary euthanasia is not permissible. To make some progress on this issue ethicists should take a closerb look at the voluntary-involuntary distinction and determine, in greater detail, the conditions unde्for which euthanasia can reasonably be characterised as voluntary.

Neil Campbell, PhD, is a Sessional Instructor in the Department of Philosophy, University of Calgary, Alberta, Canada.

\section{News and notes}

\section{Biomedicine, the Family and Human Rights}

The International Society of Family Law is holding a regional conference, Biomedicine, the Family and Human Rights, from Friday 27th of August to Monday 30th August, 1999. Topics incude: Preimplantation genetic diagnosis; genetic engineering; sex selection; cloning; assisted reproductive technology; embryo research; surrogacy; the Council of Europe Convention on Human Rights and Biomedicine; family law and ethics; parenthood, duties and responsibility; international legal collaboration, and practical legal problems.

For further information please contact: Ruth Deech (convenor) at St Anne's College, Oxford OX2 6HS, UK. Tel: +44 865274 820; fax: +44 865274 895; email sandra.madley@st-annes.ox.ac.uk 